\section{Combined percutaneous retrograde and peroral antegrade esophagoscopy for the treatment of complete upper esophageal obstruction}

Complete upper esophageal obstruction is a rare but significant complication of, for example, radiotherapy or caustic ingestion. It may be resolved by endoscopic techniques [1-4]. Here, we report three patients with complete or nearly complete upper esophageal obstruction after curative radiochemotherapy for head and neck cancers, in whom classic peroral insertion of a guidewire for esophageal dilation failed. However, in all of these patients, esophageal stenosis was successfully treated by the combinination of a percutaneous retrograde and a peroral antegrade endoscopic approach.

The length of the stenoses in these patients ranged from 2 to $20 \mathrm{~mm}$ ( $\nabla$ Fig. 1 ). Retrograde esophagoscopy was accomplished with an ultraslim gastroscope through an existing percutaneous gastrostomy. At the same time, peroral antegrade esophagoscopy was performed to enable diaphanoscopy-guided recanalization of the esophageal stenosis with a needle knife ( $\bullet$ Fig. 1, $\bullet$ Video 1 ). Afterward, a stomach tube was placed, and the reconstructed esophageal neolumen was allowed to heal for 2 to 4 weeks.

Subsequently, the patients have undergone conventional esophageal dilation procedures, which have been ongoing for 4 to 24 months ( $\bullet$ Fig. 1). Meanwhile, all the patients can be nourished orally and have experienced a significant increase in body weight and improvement in quality of life. No relevant complications have been observed in these patients during the entire course of endoscopic treatment.

In conclusion, the combination of a percutaneous retrograde and a peroral antegrade endoscopic approach can be safe and efficient for the treatment of complete upper esophageal stenosis.

\section{Endoscopy_UCTN_Code_TTT_1AO_2AD}

\section{Competing interests: None}

\section{Christian M. Lange, Bernd Kronen- berger, Johannes Hausmann, Stefan Zeuzem, Jörg Albert}

Medizinische Klinik 1, Universitätsklinikum Frankfurt, Frankfurt, Germany

\section{References}

1 Dellon ES, Cullen NR, Madanick RD et al. Outcomes of a combined antegrade and retrograde approach for dilatation of radiationinduced esophageal strictures (with video). Gastrointest Endosc 2010; 71: 1122-1129

2 Garcia A, Flores RM, Schattner M et al. Endoscopic retrograde dilation of completely occlusive esophageal strictures. Ann Thorac Surg 2006; 82: $1240-1243$

3 Maple JT, Petersen BT, Baron TH et al. Endoscopic management of radiation-induced complete upper esophageal obstruction with an antegrade-retrograde rendezvous technique. Gastrointest Endosc 2006; 64: $822-828$

4 Mavrogenis G, Moreels TG, Chevaux JB et al. Recanalization of a complete postradiation esophageal obstruction with endoscopic submucosal dissection techniques. Gastrointest Endosc 2015; 81: 1476

\section{Bibliography}

Dol http://dx.doi.org/

10.1055/s-0034-1393041

Endoscopy 2015; 47: E531

(c) Georg Thieme Verlag KG

Stuttgart · New York

ISSN 0013-726X

\section{Corresponding author}

Jörg Albert, MD

Medizinische Klinik 1

Universitätsklinikum Frankfurt

Theodor-Stern-Kai 7

60590 Frankfurt

Germany

Fax: +49-69-6301-6247

J.Albert@med.uni-frankfurt.de

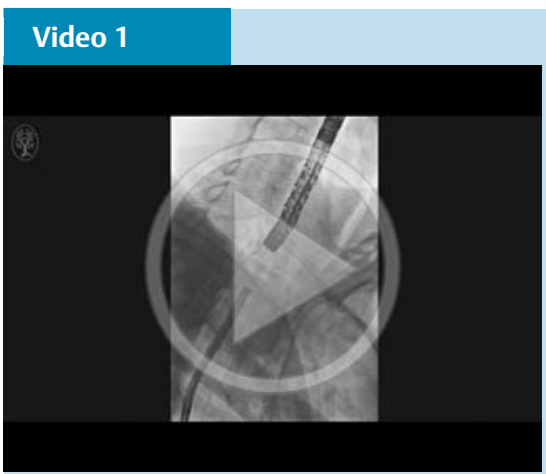

Recanalization of a long, complete upper esophageal stenosis by a combined peroral antegrade and percutaneous retrograde endoscopic approach.
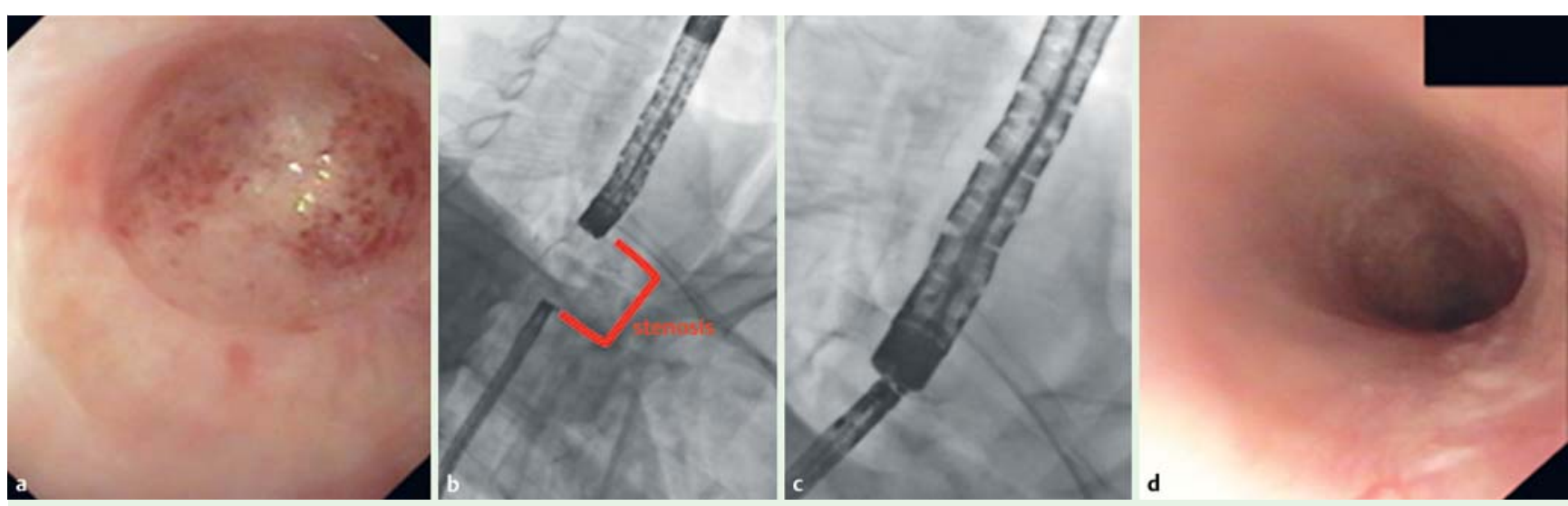

Fig. 1 Complete upper esophageal stenosis in patient No. 3 after radiotherapy for head and neck cancer. a Endoscopic view during peroral antegrade access. b Combined peroral antegrade and percutaneous retrograde esophagoscopy before esophageal recanalization with a needle knife. c After esophageal recanalization with a needle knife. $\mathbf{d}$ Recanalized esophageal stenosis after a subsequent conventional dilation program, which has been ongoing for 4 months. 